\title{
EL MITO DE "LOS HERMANOS AYAR" Y EL MITO DE RENÉ GIRARD: INTERPRETACIÓN GIRARDIANA DE UN MITO DE ORIGEN DE LOS INCAS
}

Recibido: 2-10-2016

Aprobado: 18-1-2017

\author{
Harold Hernández Lefranc \\ Universidad Nacional Mayor de San Marcos \\ Universidad Norbert Wiener
}

Antropólogo licenciado y magíster por la PUCP; tiene estudios de doctorado en la UNMSM, donde es docente TP de cursos de teoría antropológica y etnografía comparada. Es director del Centro de Investigación y del Fondo Editorial, de la Universidad Norbert Wiener, de Lima, los cuales producen una Revista de Investigación, y han editado nueve títulos de temas vinculados a las líneas de la Universidad. Sus trabajos personales de investigación han versado principalmente sobre ideología religiosa, tanto andina, como urbana popular, y protestante o paracristiana. Es autor de diecisiete papers, publicados en libros y revistas vinculados a la disciplina. Fue miembro del comité directivo del Museo de Arqueología y Antropología de la UNMSM, el cual entre 2003 y 2007 administró el museo referido, activó su producción editorial y generó curadurías. Ha hecho aportes a Micromuseo, para el cual, entre otras cosas, elaboró un ensayo sobre un ritual de violencia en la región surandina peruana, takanakuy, y donde sustenta que la violencia ritualizada controla la violencia indiscriminada. $\mathrm{Ha}$ hecho curadurías, elaborado folletos curatoriales, elaborado textos para catálogos de exposición, y presentaciones de libros.

hglefranc@hotmail.com

\section{RESUMEN}

La pretenciosa teoría del mito de René Girard († 2015) involucra el mito con la génesis de la cultura y la sociedad, y con los periódicos y cíclicos espacios de crisis de las mismas, en los cuales estos se generan procesos de persecución. Precisamente el testimonio de la persecución, en las sociedades mítico-rituales, halla Girard, es el mito. El mito fundacional de "Los hermanos Ayar", en sus diversas versiones testimoniadas por cronistas, narra una violencia, la cual remitiría, si seguimos la argumentación de nuestro autor, a una violencia real. Lo que pretendo es analizar las diversas versiones de este mito andino, en especial el proceso que sufre Ayar Cachi, a la luz de la teoría de Girard, para explicar el modelo universal de la génesis de la sociedad y la cultura y su recuerdo ejecutado a través del ritual.

Para este objetivo haré lo siguiente: Sintetizar la teoría del mito de Girard. Presentar las distintas versiones del mito de los hermanos Ayar. Demostrar cómo las diversas versiones del mito andino remiten a una perspectiva de persecución. Evidenciar, como ejemplo, cómo la fundación del Cusco del mito andino sigue el modelo del mito que descubre Girard para con la fundación de Henoc del libro del Génesis. Y presentar breves consideraciones para alimentar la legitimidad de esta interpretación del mito.

Palabras clave: Mito, Mito de los hermanos Ayar, Mito de origen, René Girard.

\section{EL MITO}

Aquello a lo que podríamos llamar teoría de la religión de René Girard, se expone más o menos sistemáticamente en tres publicaciones fundamentales: La violencia y lo sagrado [1972] (1998), El misterio de nuestro mundo [1978] (1982) y El chivo expiatorio [1982] (1986). Partiendo de las ideas sobre la sociedad y cultura 
humanas, y sobre la naturaleza de la religión, en lo fundamental, de E. Durkheim [1912], S. Freud [1913] y C. Lévi-Strauss [1949] [1962a] [1962b] [1964], Girard critica acerbamente la producción de estos autores. Pero una consideración elemental de la que parten estos autores y que rescata nuestro autor es que la religión no es un epifenómeno, fruto simplón de ideologías que pretenden manipular la buena voluntad de los ignorantes o incultos. -Pienso aquí en el concepto de ideología en el sentido al que K. Mannheim llama "particular", por oposición al sentido al que llama "total" (2004: p. 89 y ss); es decir, no ideología como instrumentalización más o menos consciente de la buena voluntad de los semejantes y que obedece a intereses particulares-. Así, la religión, al menos en Durkheim, como en Girard, funda la sociedad y la cultura humanas.

Siendo que lo que intento racionalizar es el mito de "Los hermanos Ayar", debería partir del concepto de mito para sintetizar la teoría de nuestro autor; pero el mito tiene una compleja imbricación con el ritual, de modo que debo referir a este: Girard halla una notabilísima unidad estructural de las prácticas rituales en las diversas culturas humanas del orbe; y halla que esta siempre se vincula a matar a los semejantes, o a ejercer violencia sobre víctimas en principio inocentes: "...existe una relación entre las formas rituales y la tendencia universal de los hombres a transferir sus angustias y sus conflictos a unas víctimas arbitrarias." (1982: p. 159).

Esta semejanza universalmente comprobable de la violencia del ritual, atenuada a lo largo de la historia de maneras muy sutiles, hace que el autor se pregunte si en el inicio, en la fundación de la cultura, se produjo algo decisivo y tan imborrable para que haya quedado como huella, si bien transfigurada. Y rescata la hipótesis de Totem y tabú, de S. Freud [1913]: el acontecimiento original debió ser un homicidio. El mismo tipo de homicidio en todas las sociedades, pero que no ha ocurrido de una vez por todas (Cfr. Girard, 1998: p. 100); es decir, se trata de un hecho más que histórico, estructural.

Hay otra constante de la humanidad, es decir, de todas las sociedades: la pendularidad de tiempos de relativa paz, orden 0 estructuración social más o menos legítima, versus formas de violencia indiscriminada, desmesurada, anómica, desestructuración social e ilegitimidad; y el hecho de que el orden reposa en las diferencias (llamémosle estructura social). Aquí es preciso tener presente aquello a lo que se llama teoría mimética y que impregna los tres libros de Girard: El ser humano es gregario; pero a falta de un 
instinto natural que le indique el comportamiento en sociedad, la mímesis es lo que compulsa su comportamiento, es decir, la imitación de los semejantes. Pero precisa y paradójicamente el orden social descansa en las diferencias, antítesis de la imitación. El deseo mimético, base del aprendizaje, y que genera competitividad social, es resistido con la prohibición, la ley, la regla, finalmente, el tabú, sustento del orden y la paz social. Así, en el orden social hay una resistencia a la indiferenciación, que es esta precisamente el punto de partida de lo social. El orden reposa en las diferencias. Y cuando estas se desdibujan, acontece la violencia indiferenciada, excesiva, mimética, imitativa, reciprocidad de violencias, aquello a lo que el autor llama crisis sacrificial. Aquí la función de la religión: la religión impide el retorno de la violencia recíproca, espontánea, disgregadora, a través del ritual, del sacrificio. La religión tiene por objeto el mecanismo de la víctima propiciatoria; ejecuta una violencia unánime, dirigida contra la víctima, que estructura, que funda, que ordena, que limita la violencia virulenta y su círculo vicioso. Su función: mantener la violencia fuera de la comunidad, botar la crisis fuera de la sociedad, y fundar la violencia sacrificial. La víctima propiciatoria impide la desestructuración. Es la tesis del linchamiento fundador. (Cfr. Girard, 1998: p. 97 y ss).

Aquí el mito: este es un informe transfigurado de la génesis real de la cultura que recuerda siempre una violencia colectiva, de todos contra uno, en el origen de la cultura. Es la perspectiva de los linchadores, reconciliados por la unanimidad de la transferencia a la víctima sacrificial. ¿Transferencia de qué? Del mal, de la culpa, de la violencia indiferenciada. Pero el mecanismo completo consiste en lo siguiente: ejecutado el rito, la víctima se diviniza, los ejecutores se concilian con ella y se le atribuye el retorno de la paz y el orden. El linchamiento cumple una función importante en la estructuración de las sociedades: reconcilia a la comunidad. Así, la mitología es la perspectiva transfigurada sobre el linchamiento, que implica un efecto conciliador; y el ritual, no solo recuerda, sino que permite a los linchadores reproducir el acontecimiento reconciliador, que funda el orden y la paz sociales. (Cfr. Girard, 1982: p. 119 y ss).

Desarrollo de la teoría del autor que pudiera no interesar en principio en esta sustentación es la siguiente: los textos de persecución desde la Edad Media, y que "explican" los desastres naturales, epidemias o desórdenes sociales, en lo fundamental por los judíos, son formas a medio camino entre la mitología y la desmitologización del presente desacralizado y donde los mecanismos sacrificiales son 
marcadamente imperfectos. Halla que en los textos de persecución se evidencian cuatro estereotipos de la persecución: 1. Hay una crisis social o cultural que significa indiferenciación generalizada; 2. Acontecen crímenes "indiferenciadores"; 3. Los responsables de los crímenes poseen signos de selección victimaria; 4. Existe violencia propiamente. Hay pogromos o linchamientos en la totalidad del planeta; pero en principio el fenómeno de la persecución no se hallaría en las sociedades míticas o frías o segmentarias o aquellas que trabajan los etnólogos. Girard afirma y sustenta que los testimonios de persecución lo constituyen los mitos. Siendo que la mitología es, como vimos, violencia colectiva contra víctimas arbitrarias, aquello a lo que el autor llama significaciones en los textos de persecución (1982: p. 145), también se encuentran en los mitos: 1. la comunidad está en crisis (peste, desorden, violencia, muerte; o bien en los mitos de los pueblos etnológicos, el caos o desorden previo al orden que decidirán los héroes míticos); 2. Los judíos cometen crímenes contra la naturaleza (en los mitos, las víctimas poseen signos de distinción, como cojera, ceguera, gigantismo, enanismo, bisexualidad, hermafroditismo, etc.; siempre hay exceso o defecto monstruosos); 3. Hay violencias colectivas contra ellos; 4. Las violencias ejecutadas (pogromos o linchamientos) eliminan (desde una perspectiva emic, diríamos) la polución o el peligro, y se accede al orden o sanidad. La única diferencia entre textos de persecución y mitos es que en los mitos se sacraliza a la víctima; los perseguidores se limitan a matarla. ¿Por qué? La explicación completa excede el objetivo de la presente sustentación, pero se parte de la idea de que "...la sociedad que produce textos de persecución es una sociedad en vías de desacralización." (1982: p. 154).

¿Pero por qué interesa este desarrollo de la teoría en los textos de persecución? Porque esta explicación evidenciaría su universalidad: el autor rescata dos mitos vinculados a la génesis de la cultura que Lévi-Strauss señala en El totemismo en el presente: uno ojibwa, de Norteamérica, y otro tikopia, de Melanesia; y suma uno yahuna, del noroeste del Brasil, y nada menos que Bacantes, de Eurípides. En todos ellos hay todos contra uno, violencia colectiva, linchamiento. Rescato esquemáticamente a los dos primeros mitos para que se evidencie la similitud estructural con "Los hermanos Ayar":

El mito ojibwa: cinco clanes primitivos remontan a seis seres salidos del océano; uno tenía los ojos vendados. Tenía ganas de mirar a los hombres; se quitó la venda; miró a un hombre y este murió como fulminado por un rayo. Sus compañeros lo obligaron a regresar al 
fondo del mar. Los cinco restantes convivieron con los hombres y originaron los cinco clanes. El mito tikopia: los dioses no se distinguían de los hombres; un dios extranjero visitó a los tikopia; los dioses tikopia prepararon un festín, pero antes organizaron una competencia de velocidad; el extranjero fingió tropezar y herirse, para lanzarse sobre la comida, parte de la cual se llevó; la familia de los dioses lo persiguió; este cayó de verdad y los dioses rescataron cuatro tipos de fruto, que permanecieron para los hombres.

Entonces, "...el mecanismo productor de lo religioso [es] la transferencia colectiva contra la víctima primero execrada y luego sacralizada..." (Girard, 1982: p. 208).

\section{EL MITO DE "LOS HERMANOS AYAR"}

Rescato las distintas versiones de "Los hermanos Ayar" de lo que puede llamarse ciclo mítico de los Ayar, compilación de H. Urbano († 2014), de la publicación Wiracocha y Ayar. Héroes y funciones en las sociedades andinas (1981). El segmento propiamente tal, la segunda parte del libro, acopia una suma de cuarenta y dos versiones, de cronistas, de entre el siglo XVI y el siglo XVII (entre 1542 y 1653). De estas versiones rescato cuatro, pues involucran de una manera orgánica la presencia de personajes que explican la fundación del Cusco por los hermanos Ayar. Se trata de las versiones a las que Urbano enumera para su publicación como los mitos 19, 25, 33 y 38 . Sintetizo para con esta exposición estos llamados mitos, y rescato lo pertinente:

\section{a. El origen de los Incas según Juan de Betanzos, M19, de la fuente Suma y narración de los Incas:}

Salieron de lo que se llama Pacaritambo cuatro hombres con sus mujeres: Ayar Cache y su mujer Mama Guaco; Ayar Oche y su mujer Cura; Ayar Auca y su mujer Ragua Ocllo; y Ayar Mango, llamado después Mango Cápac y su mujer Mama Ocllo. Llegaron a Guanacaure, cerca del Cozco. Ayar Cache tiró una piedra con una honda; derribó un cerro e hizo una quebrada; y continuó haciendo lo mismo tres veces. Viendo esto sus hermanos, lo echaron de su compañía, porque era de grandes fuerzas y valor; por tanto, los dominaría: le mandaron a la cueva de donde salieron; al entrar le cerraron la salida. En Guanacaure acordaron que uno de ellos quedase como ídolo; y que el resto que poblase la tierra le adorasen; y que este les guardase y aumentase y diese hijos. Se levantó Ayar Oche y mostró unas alas; y dijo que él se quedaría por ídolo, para 
que hablase con el sol su padre; y le dijo a Ayar Mango que se nombrase Mango Cápac, que así lo mandaba el sol. Y tornó Ayar Oche piedra. Mango Capac y Ayar Auca fueron al pueblo del Cozco. Sembraron maíz sacado de la cueva de donde salieron. Luego murió su compañero Ayar Auca. Y tuvo Manco Capac un hijo, Sinchi Roca.

\section{b. El origen de los Incas según Pedro Cieza de León, M25, de la fuente El señorío de los Incas:}

Aparecieron en un lugar no muy lejos del Cuzco, Pacarec Tampu, tres hombres y tres mujeres. Salieron Ayar Uchu, Ayar hache auca y Ayar Manco; y Mama Huaco, mama Cora y Mama Rahua. Algunos indios dicen que eran más los nombres. Ayar Cachi (cuarto hermano) era muy valiente; con una honda derribaba cerros. A los hermanos esto les parecía una afrenta; y motivados por la envidia le rogaron dulcemente y con engaño que volviese a entrar a la cueva para traer cierto objeto. Ayar Cachi quedó dentro. Les pesó a los hermanos haber procedido así con Ayar Cachi, que por otro nombre dicen llamarse Huanacaure.

Asentados los hermanos en un lugar vieron venir por el aire a Ayar Cachi con grandes alas. Llenos de gran temor quisieron huir; pero este les quitó el pavor: les dijo que no teman; que había venido para que sea conocido el imperio de los incas; que dejen el lugar donde estaban y funden el Cuzco, que es lo que ha de valer; que el sol sea el más alabado. Instó a ser santificado y adorado por los descendientes de los hermanos, y que se le llame Guanacaure. Les invita a que en pago por sus buenas obras para con ellos "me adoréis por Dios y en él me hagáis altares, donde sean hechos los sacrificios; y haciendo vosotros esto, seréis en la guerra por mí ayudados". Y señal de esto sea el que se horaden las orejas como las tiene Ayar Cachi.

Luego de la turbación de los hermanos, respondieron que estaban contentos de hacer lo que se les mandaba; y fueron al cerro Guanacaure, al cual tuvieron por sagrado. Ayar Cachi le dijo a Ayar Manco que fundase el Cuzco, "sin olvidar de venir a hacer sacrificios a aquel lugar". Ayar Cachi y otro hermano se convirtieron en figuras de piedra. Vio esto Ayar Manco y tomando a las mujeres fue a donde ahora es el Cuzco a fundar la ciudad, nombrándose en adelante Manco Cápac, señor rico. Llegado al Cuzco pedía al sol que le favoreciese y mirando hacia el cerro Guanacaure pedía lo mismo a su hermano, "que ya lo tenía y reverenciaba por dios". Fundó la nueva ciudad. 


\section{c. El origen de los Incas según Pedro Sarmiento de Gamboa, M33, de Historia Índica:}

En Pacaritambo hay un cerro de nombre Tambotoco. Había tres ventanas. De la última salieron cuatro hombres y cuatro mujeres, que se llamaron hermanos. Ellos decían de sí que el Viracocha los había criado para ser señores. Sus nombres, Mango Capac, Ayar Auca, Ayar Cache y Ayar Ucho; las mujeres Mama Ocllo, Mama Guaco, Mama Cura y Mama Raua. Estos ocho hermanos fueron a buscar tierras fértiles. Mango Capac tuvo ayuntamiento carnal con su hermana Mama Ocllo.

En determinado lugar los hermanos hicieron un acuerdo para apartar de sí a uno de los cuatro hermanos, Ayar Cache, porque como era feroz y fuerte y diestro con la honda y hacía travesuras y crueldades, temían los hermanos que por mala compañía y travesuras se les deshiciesen las compañías y quedasen solos. Le dijeron que regresase a la ventana por donde habían salido y quedó encerrado. A los hermanos les pesó lo que hicieron porque como era valiente, pudiese afrontar la guerra contra eventuales enemigos. Hicieron llanto por él. Era tan fuerte que a cada pedrada hacía una quebrada.

Los hermanos acordaron que Mango Capac fuese cabeza de todos; Ayar Uchu quedase por guaca para su religión; y Ayar Auca fuese a tomar posesión de tierra a donde lo mandasen. Llegaron a un lugar guanacauri, donde vieron una guaca, y pidieron a Ayar Uchu quitarla; pero este quedó pegado a la guaca. Los hermanos fueron a rescatarlo, pero no era posible hacerlo. Este les dijo que vayan felices, que serán grandes señores; pero les pide que en pago a su voluntad, en fiestas y ceremonias sea honrado y venerado; y quedó convertido en piedra. Los ingas lo constituyeron como guaca y le pusieron de nombre Ayar Ucho Guanacauri.

Los hermanos restantes quedaron tristes por Ayar Ucho y por la muerte de Ayar Cache; por eso temen los del linaje de los incas llegar a Tambotoco. En el valle del Cuzco armaron caballero al hijo de Mango Capac, Cinchi Roca, y le oradaron las orejas. Lloraron el que tuvieran que abandonar a Ayar Uchu y ahí inventaron el llorar a los muertos.

Mango Capac vio una señal de piedra donde ahora está el monasterio de Santo Domingo y le dijo a Ayar Auca: ve ahí volando; le nacieron alas; y tomó posesión del lugar. Pero ahí se convirtió en piedra. De ahí el proverbio Ayar Auca cuzco guanca. Otros dicen que 
el nombre de Cuzco es porque en donde se enterró a su hermano Ayar Cache hizo Ilanto; pero eso no es creíble porque Ayar Cache no fue enterrado en el Cusco.

\section{d. El origen de los Incas según Miguel Cabello de Valboa, M38, de Miscelánea antártica:}

Pasado el diluvio universal, salieron de Pacaritambo ocho hermanos, cuatro varones y cuatro hermanas (se puntualiza aquí que son todos, los ocho, hermanos). Mango Capac conoció sexualmente a su hermana Mama Ocllo y la preñó, de modo que al evidenciarse el embarazo generó escándalo en los hermanos, pero al nacer el infante hubo alegría. Sin embargo, el hermano Ayarauca siguió manifestándose agraviado y abominando el hecho como prohibido, de modo que el resto de hermanos le cobró odio a Ayarauca; y lo enviaron con engaño al lugar de donde salieron, y lo encerraron. Aducían ellos que lo hicieron porque iba tirando piedras, derribando montes, haciendo caer piedras sobre labranzas, y que temían que destruyese el mundo. Los hermanos Ilegaron al cerro Guanacauri, donde había un sacerdote hechicero. Ayarcache, uno de los hermanos, fue enviado para prenderlo, pero quedaron pegados sus manos y pies a la tierra. Se quejó del daño que supuso haber sido enviado a este lugar; pero presagió a los hermanos prosperidad y ser señores de muchas tierras; les pidió sacrificios, bailes y ofrendas. Les dijo que quedaría ahí por padre y origen de su descendencia, y se convirtió en piedra. Fue llorado por los hermanos, y vinculado a este sufrimiento el origen de celebraciones por el nacimiento de los hijos y descendientes.

\section{LA PERSPECTIVA DE LA PERSECUCIÓN Y LOS CUATRO ESTEREOTIPOS DE PERSECUCIÓN, EN EL MITO DE “LOS HERMANOS AYAR"}

Girard plantea que el mito, en las sociedades mítico-rituales, es decir, no históricas, es testimonio y evidencia de persecuciones colectivas, las cuales estas son un reiterado mecanismo que funda el orden social y cultural, y que lo refunda periódicamente ante procesos de crisis social y cultural: "... todos los mitos se arraigan necesariamente en violencias reales, contra víctimas reales." (Girard, 1986: p. 36). No abundaré en esta aserción, sobre la realidad histórica de las violencias a que remiten los mitos, que no es el tema de esta ponencia, si bien podría presentarse la sustentación epistemológica y metodológica del autor: aplicar la interpretación universalmente admitida para los textos de persecución a los textos mitológicos: en 
los textos de persecución la inverosimilitud de las acusaciones a los judíos refuerza la verosimilitud de la violencia colectiva. Como en los mitos, la verosimilitud y la inverosimilitud se combinan para sugerir que estamos ante una persecución real, pero falseada y transfigurada, porque se trata de la perspectiva de los perseguidores (Cfr. Girard, 1982: p. 147).

Puede reforzarse esto con una suma de constantes de las diversas versiones del mito de los hermanos Ayar, que solo señalo: no interesa si son tres o cuatro los hermanos varones, ni sus nombres, sino sus funciones: uno de ellos es acusado real o falsamente de desordenar o destruir el mundo o de, haciendo esto, generar enemigos, y consecuentemente es, fruto de un complot, eliminado. La real motivación es la envidia o el temor de subordinarse a este poderoso; en una de las versiones es evidente que la acusación es falsa, y que la real motivación de eliminarlo es acallar un escándalo que precisamente ha permitido la reproducción del grupo: el incesto. En todos los casos, la violencia contra el hermano deriva tácita o evidentemente en culpa y mala conciencia. Pero esta genera la reconciliación, que a su vez parece condición del éxito de la fundación de Cusco, pero solo a costa de transformar al eliminado contra el cual se ha complotado, en nada menos que dios, y a quien se ofrenda. Pretendo aquí señalar los estereotipos de persecución que aparecen en los resúmenes de estas versiones del mito andino:

1. Crisis social y cultural: indiferenciación generalizada. Es aquello a lo que el autor llama también disolución conflictiva: la creación del mundo y el diluvio, del origen de los tiempos es asimilable a la crisis social. Un momento aun no ordenado es un momento desordenado; hace falta el orden. En diversas mitologías se usa la figura de los hermanos o gemelos enemigos: Caín y Abel, Jacob y Esaú; José y sus hermanos. Puede asimilarse también a la peste que asola Tebas, de Sófocles. En Betanzos, Cieza, Sarmiento y Cabello, acontece la idea de que estos hermanos salidos de una cueva, llamada casa del producimiento, deben concretar una tarea, sin la cual no hay orden; el orden está por hacerse. Aún no se funda esta acción, no hay un carácter de definitividad. Pero ese orden debe fundarse en una violencia, que aún no acontece. 2. Crímenes "indiferenciadores". Haría falta discutir la "traducción" que los cronistas han ejecutado sobre los diversos testimonios de este "mito", tema en el que no entraré aquí. Pero es indudable la moralización cristiana que se ha hecho. Lo cierto es que en las cuatro versiones que sintetizo, uno de los hermanos (Ayar Cachi en las tres primeras; Ayarauca en la cuarta) 
adolece de desmesura, de extremada fuerza, indiferenciadora, que genera peligro constante o sensación de peligro constante en sus compañeros, indiferenciación por tanto; destruir el mundo dice la versión de Cabello. 3. Los autores de los crímenes con signos de selección victimaria. En Ayar Cachi (o bien Ayarauca) la extremada fuerza, violenta, potencialmente ordenadora (abre quebradas, que sirven para la agricultura), lo hace un monstruo; constituye una desmesura. 4. La violencia misma: el obrar con violencia de parte de los hermanos contra Ayar Cachi, pero que se extiende a violencias sacrificiales también sobre Ayar Uchu y Ayar Auca, purifica a la comunidad y se elimina la polución. Ordena. Sanciona. Funda. Diferencia. Pero detengámonos un instante en la resolución de las muertes de los hermanos, o más bien transformaciones, o más bien metamorfosis, para usar un término más grecoromano:

En Betanzos, luego de deshacerse de Ayar Cachi, el resto acuerda que Ayar Oche transforme en ídolo, dios, para que el resto lo adorase, al hermano y poblase la tierra, es decir funde la cultura, y que el ídolo tuviera comunicación con el padre, el sol, dios. En Cieza, Ayar Cachi, luego de la violencia contra él, regresa pero con la misión de anunciarles que deben fundar el Cusco, y que Ayar Cachi será el intercesor para que esto concrete; pero les pide ser venerado, que lo hagan dios. $Y$ estos inmediatamente obedecen. Pero además el sacrificado insiste en la fundación de la cultura, del Cusco; esto concreta y se le hace altares y sacrificios al hermano, ahora dios. En Sarmiento, Ayar Cachi hace travesuras, es un deceptor claramente, un trickster; y Ayar Auca y Ayar Uchu se suman al sacrificio, a la transformación en ídolos, en dioses, permitiendo o favoreciendo la fundación del Cusco. En Cabello, hay una moralización marcadamente cristiana con la insistencia en la abominación del incesto y en reconocimiento explícito de que los varones y las mujeres son hermanos; uno de ellos transforma en piedra y transforma de hermano en padre y augura prosperidad.

En las cuatro versiones los hermanos urden una conspiración contra uno de ellos con una acusación o falsa acusación; se ejerce violencia colectiva, de todos contra uno, en lo fundamental no por mala voluntad, sino porque sinceramente creen que es este es un peligro; pero se reconcilian finalmente con la víctima y con ellos mismos, con pena o arrepentimiento, tornando a la víctima como dios y permitiendo con esto la concreción del orden que es la fundación de la cultura: el Cusco. Es el linchamiento fundador. -Volvamos solo un instante al mito ojibwa: uno de los seis seres salidos del océano 
comete un exceso, violencia disgregadora, caótica, accidental, indiferenciadora; es regresado al mar, a la indiferenciación, y los cinco restantes fundan los cinco clanes, el orden social. $Y$ ahora volvamos a mito tikopia: el dios extranjero comete un exceso, una torpeza indiferenciadora, glotonería. Su torpeza en la huida y desaparición funda cuatro tipos de alimentos tikopia-.

En síntesis: 1. disolución conflictiva; 2. todos contra uno (sacrificio que torna a la víctima en fundamento del orden); 3. prohibiciones y rituales: la víctima tornó dios (esta fundó el orden social y cultural).

\section{LA FUNDACIÓN DEL CUSCO POR MANCO ES COMO LA FUNDACIÓN DE HENOC, POR CAÍN, DEL LIBRO DEL GÉNESIS}

Como parte del argumento de que se trata de una constante universal, solo señalo lo siguiente: En el libro del Génesis 4: 16-18, se dice que luego de asesinato de Abel, salió Caín de delante de Jehová, y habitó en tierra de Nod, al oriente de Edén. Y conoció Caín a su mujer, la cual concibió y parió a Henoch: y edificó una ciudad, y llamó el nombre de la ciudad del nombre de su hijo, Henoch. Y á Henoch nació Irad, e Irad engendró a Mehujael, y Mehujael engendró a Methusael, etc. Luego, en Los hermanos Ayar, cuatro hermanos y respectivas esposas emergen de la cueva de un cerro y buscan fundar un pueblo; uno de ellos es considerado peligroso y es asesinado; pero es este mismo el que permite la fundación de una ciudad, Cusco, y augura la descendencia.

Señalar solo que en los dos mitos, más allá de detalles episódicos o las particularidades inéditas del judeocristianismo (asumirse la perspectiva de la víctima), remiten a una suma de momentos: disolución conflictiva o violencia colectiva o caos; ejercicio de la violencia unánime o unilateral contra una víctima; y la asunción de un orden, que es la fundación de una ciudad y la descendencia.

\section{CONSIDERACIONES COMPLEMENTARIAS}

Una suma de consideraciones que solo señalo, y en otro espacio desarrollaré, se abren luego de esta lectura del mito andino desde la teoría del mito de Girard: 1. El ciclo mítico de los hermanos Ayar, con su desarrollo argumental o significaciones o rasgos semejantes a los arquetipos de la persecución, legitima la inteligibilidad del mismo, así como la teoría o hipótesis de este autor. 2. Es legítimo comparar este mito con los propios de las génesis de otras áreas culturales: pienso en la fundación de Tebas por Cadmo, por ejemplo. 3. Es pertinente sumar otros mitos andinos de génesis, a esta interpretación, no para 
alimentar la teoría de Girard en lo fundamental, sino para intentar hacerlos inteligibles o más inteligibles. 4. Hay que poner en cuestión la pertinencia de interpretar los mitos desde funciones ingenuas, como las moralizaciones espontáneas que nacen del sentido común. 5. Lo que creo se ha evidenciado en este texto como medular es la casi irreprimible necesidad de la constitución humana, social y cultural, de fundar el orden en la violencia y la economía sacrificial.

Corolario de esto como reflexión para el presente es que puede ser que la crisis sacrificial que en el presente desde la increencia se experimenta, se debe a los intentos de neutralizar la violencia indiscriminada, que exacerban más la violencia: como podría decir Girard, si bien desde el ritual hay que matar y seguir matando para no saber que se mata, desde la ausencia de ritual el intento compulsivo por evitar la víctima propiciatoria, puede derivar en violencia recíproca.

\section{REFERENCIAS BIBLIOGRÁFICAS}

Durkheim, E. [1912] (1968) Las formas elementales de la vida religiosa. Buenos Aires: Shapire.

Freud, Sigmund. [1913] (1985) Totem y tabú. Madrid: Alianza Editorial.

Girard, René. [1972] (1998) La violencia y lo sagrado. Barcelona: Anagrama.

Girard, René. [1978] (1982) El misterio de nuestro mundo. Claves para una interpretación antropológica. Salamanca: Sígueme.

Girard, René. [1982] (1986) El chivo expiatorio. Barcelona: Anagrama.

Lévi-Strauss, Claude. [1949] (s/f) Las estructuras elementales del parentesco. Buenos Aires: Paidós.

Lévi-Strauss, Claude. [1962a] (1984) El pensamiento salvaje. México: FCE.

Lévi-Strauss, Claude. [1962b] (2011) Le totémisme aujoud’hui. París: PUF.

Lévi-Strauss, Claude. [1964] (1982) Mitológicas. Lo crudo y lo cocido. México: FCE.

Mannheim, Karl. (2004) Ideología y utopía. Introducción a la sociología del conocimiento. México: FCE.

Urbano, H. (1981) Wiracocha y Ayar. Héroes y funciones en las sociedades andinas. Cuzco: CBC. 